[Thomson, C., Brown, D., Jones, E., \& Manins, E. (2000). The Development of Resource Teachers in New Zealand: A Quarter Century of Paradigm Change. New Zealand Annual Review of Education, 9, 23-42]

\section{The Development of Resource Teachers in New Zealand: A Quarter Century of Paradigm Change}

\author{
Charlotte Thomson, DON Brown, ElizABETH JONES \\ AND ELIZABETH MANINS
}

\section{Abstract:}

The purpose of this paper is to trace the development of the role of Resource Teachers Learning and Behaviour (RTLB) from its genesis in the establishment of the Guidance and Learning Units in 1975, through the establishment of support teams and Resource Teacher Special Needs to its present form. This development is placed in the context of two paradigm shifts that have impacted on special education practice and policy in New Zealand over the last 25 years. The somewhat halting progress of special education is explained by the multi-paradigmatic nature of the social sciences and the consequent clashes of opinion and tensions that result from it.

National guidelines have made schools responsible for the learning of all children. These guidelines addressed issues of equity, rights, values and devolved accountability and consequently included those students with special teaching needs who had previously been considered separately. These guidelines therefore enabled changes in special education to take place. The paper goes on to outline the rationale and structure of the training programme for RTLB and discusses some of the tensions still remaining in the implementation of the role.

$\mathrm{T}$

his year will see the implementation of the final stages of the latest special education reform in New Zealand, Special Education 2000 (SE2000) which aims "to achieve, over the next decade, a world class inclusive education system that provides learning opportunities of equal quality to all students" (Ministry of Education, 1996, p. 5). Pivotal to the successful implementation of the vision behind this policy will be the work of approximately 740 special education teachers, Resource
Teachers: Learning and Behaviour (RTLB). These teachers will provide support for students who "are at risk of low achievement due to learning and/or behaviour difficulties; and their teachers" (Ministry of Education, 1999, p. 33). An indication of the seriousness with which this role has been perceived in the context of the reforms is that significant funding has been allocated to the professional development of these teachers.

This provision, to support students with mild to moderate need, rests on the shoulders of previous policy and practice. This paper will trace the development of the RTLB role from 1975 to its present form and will attempt to clarify its rather chequered history in the context of two shifting paradigms in education and society in general.

\section{Multiple Paradigms}

For the past fifteen years special education has been characterised by frequent reviews and major policy changes. Mitchell (1999) describes it as a "battleground" for vigorous debate of issues that are not only specific to special education but also more general, "with special education becoming the proxy for wider concerns" (p. 199).

Mitchell (1999) goes on to postulate that this reflects the coalescence of a series of paradigm shifts in special education as well as in the education system and the broader public sector. This notion of a paradigm shift in special education has been advanced previously by a number of educators and administrators both internationally (Skrtic, 1995, 1991, 1986) and in New Zealand (Ballard \& McDonald, 1998; Davies \& Prangnall, 1999; Fancy, 1999; Moore et al., 1999; Thomson, 1998). Paradigm shifts in education in general, particularly those in the administration of education in New Zealand, clearly impact on special education and add complexity to an already complex situation.

This paper focuses on two of the major paradigm shifts evident in education and the broader public sector. The first is the move away from the traditionally dominant paradigm - what is known as the functional limitations or deficit perspective - to the inclusion/ecological paradigm. The functional limitations paradigm "assumes that the principal difficulties of people with disabilities reside within those individuals. The task of the educators is to fix, improve or compensate for these deficits, requiring schools to adapt, minimally, if at all, to their needs" (Thomson, 1998, p. 4). The inclusion/ecological paradigm increasingly challenges the traditional assumptions of internal causation 
and remediation of deficits and posits that "the primary problems facing people with disabilities are external rather than internal. The task of educators working within this paradigm is to alter, adapt and improve educational organisations and environments to meet the needs of all students" (Thomson, p. 4).

This new paradigm has its roots in two major movements. The first movement marks a change in our thinking, theorising and understanding of the processes involved in learning. Learning is now usually conceptualised in the literature as an interactive and contextualised process (Will, cited in Moore et al., 1999). The second movement marks the shift in values throughout the western world toward greater equity for all, and can be subsumed under the umbrella of the multi-cultural education movement which aims to address issues of race, ethnicity, gender, socio-economic class, language and disability. The challenge is to shape a culture in schools responsive not only to ethnic and racial minority groups but to those who are "economically poor, women, gays and lesbians and people with disabilities" (Sleeter, 1995, p . 83). The aim of inclusion is to work toward structural equality in educational organisations. Unlike some mainstreaming practices which have been very much part of the traditional functional limitations paradigm, the inclusion movement questions some of the fundamental suppositions of the knowledge base of special education and is fundamentally about school reform.

The second major paradigmatic shift is from central control in which the education system is administered by a central bureaucracy and its agents, to decentralisation in which the local school is the unit of management. Since 1989 we have seen the devolution of control from the Department of Education and education boards to schools. However the self management of schools has taken place within national guidelines. Mitchell (1999) notes that there remains a tension between the central and devolved paradigms. He describes this as a tension between centripetal and centrifugal forces and asserts that SE2000 encompasses both.

Because of their apparent increasing use, the terms "paradigm" and "paradigm shift" warrant explanation as they describe complex concepts. Indeed, as Lincoln back in 1985 pointed out, "Paradigm is such a popular word that to ask what, exactly, it means has become rather de trop, as though one should know already" (p. 29).

These terms came to prominence in the work of Kuhn (1962), as central elements in his challenge to the commonly held assumptions at the time about the way in which science changes. The term has been used in a number of ways. In its broadest sense, Kuhn used the term to mean a world view, "a set of explicit or implicit presuppositions or basic beliefs that scientists use to provide coherence to their picture of the world and how it works" (Ritzer, 1986, p. 7). A paradigm then is much more than a theory or a model. Our world view reflects our most basic beliefs and assumptions - what is "true", what is of value, what is the nature of things.

Skrtic (1986) offers a particularly apt metaphor for a paradigm as a special lens which enables us to see the world more clearly. However, the lens may also colour what we see and restrict our vision. A paradigm shift occurs when we change an old lens for a new one that helps us to see the world in an entirely different way.

A key point in Kuhn's position is that paradigms shift mainly because of socio-political factors. When values and attitudes change in society, old paradigms are put under strain. The new values and attitudes are inconsistent with the basic assumptions of the existing paradigm. There are political clashes between groups holding different views. The paradigm that emerges as victorious is the one that can gain the most converts, or whose converts are most powerful. Ritzer (1980) asserts that "Paradigms rise and fall as a result of subjective not objective factors" (p. 10)

Kuhn's writings emerged from the physical sciences, but his ideas have been adopted by social scientists (Ritzer, 1980). Masterman (cited in Ritzer, 1980) argues that while the physical sciences in general operate under the broad consensus of a single paradigm, social sciences are multiparadigmatic, in that several viable paradigms compete for dominance. Ritzer (1980) asserts that one of the defining characteristics of a multiparadigmatic science is that "supporters of one paradigm are constantly questioning the basic assumptions of those who accept other paradigms." (p. 12). He takes the view that paradigms can coexist in the social sciences though not peacefully.

\section{Slow Progress In Special Education}

The multiparadigmatic nature of the social sciences helps to explain some of the difficulties in making progress in special education in New Zealand. Characteristic of multiparadigmatic sciences, much time and energy has been spent in debate. Lack of consensus has slowed policy decisions. Ritzer (1980) maintains that supporters of one paradigm are "constantly defending their flanks against attacks from those who 
support other paradigms" (p. 12). This is well illustrated by the fact that it has taken twenty five years for the RTLB to become national policy, and tensions still remain.

The genesis of the RTLB can be found in the development of the guidance and learning units (GLU) in 1975 (Thomas \& Glynn, 1976). For the first time, the provision of a separate withdrawal unit for students with significant learning and behavioural difficulties at three intermediate schools was substituted with an in-class, ecological model of support focused upon a student's current performance in the context of the academic programme, teacher behaviour and peer behaviour.

This pioneering approach was developed using specifically trained teachers, supported by psychologists and a management committee comprising representatives of these professionals and the schools in the district. This development represented a paradigmatic shift away from a functionallimitations perspective towards a more inclusive/ ecological view. The model of the GLU teacher was based on the theory of applied behaviour analysis that postulates that behaviour is a function of the environment in which it occurs and is shaped by its antecedents and consequences.

At the same time as this development was taking place and the model was being adopted in other areas of the country, separate special classes for children with learning and behaviour difficulties were maintained in many schools (Brown \& Thomson, 1988). In fact, psychologists supporting GLU teachers continued to make recommendations for placement in such separate facilities whose raison d'etre could be explained by the functional limitations model. A new paradigm was emerging but the established one remained.

It was in this decade from the mid-seventies to mid-eighties that other evidence of changes in thinking and service delivery in special education were apparent. In 1975 a number of psychologists in the education service withdrew from a national survey on learning difficulties because they would not use standardised intelligence tests (D. Brown, personal notes). In the same year the Acting Chief Psychologist withdrew a long-standing request for funding to standardise the Wechsler Intelligence Scale for Children on the grounds that there was no clear educational purpose in its use (D. Brown, personal notes). By 1985 the Director of Special Education issued a memorandum to remove the requirement of standardised intelligence test scores for access to special education resources. Implicit in this decision was the recognition that differential diagnosis and categorisation were inadequate methods of identifying and addressing educational need, reflecting the inclusive/ecological paradigm. Evidence, however, of the co-existence of the two paradigms was the continuation of special classes and schools.

In the late 1980s there was a move to close many special education units and return students, teachers and resources to the mainstream (Brown \& Thomson, 1988). In Wellington, in particular, special school principals, with the support of colleagues in the school inspectorate and the psychological service, were a driving force in disbanding segregated special facilities. Impetus for this move toward more inclusive education came from the growing human rights movement throughout the western world, although it was to be another decade before the rights of individuals in society were recognised by law in New Zealand with the passage of the Human Rights Act (August 19, 1993)

As Brown and Thomson (1988) demonstrated, the move from segregation to inclusion did not proceed evenly across the country, with large variation in the rate of closure of special schools and classes evident across different geographic areas, despite a national special education administrative structure. This diversity is still evident today with, for example, approximately 20 Auckland RTLB teaching closed or partly segregated classes, while few remain elsewhere in the country. This diversity in service delivery demonstrates the co-existence of two opposing methods that reflect different paradigms-inclusion reflecting an ecological approach and segregation reflecting a functional limitations approach.

The disestablishment of the special classes was a step toward inclusion. It released the teachers to support their students in mainstream classrooms. These ad hoc arrangements resulted in a diverse range of provisions but with the special education teacher having the prime responsibility for students identified on her roll. These positions were later to be recognised formally as Resource Teachers Special Needs (RTSN).

In 1988 the Department of Education closed Campbell Park School, a large residential school for boys with behavioural and learning difficulties situated in Otekaike Valley in Central Otago. A significant number of the students at the school were young Maori from urban centres in the North Island. The move to close the school is further evidence of the growing influence of the inclusive paradigm. It was no longer seen as appropriate to uproot these youngsters from their culture and community and segregate them from the rest of society. 
The closure resulted in the next step toward a within-school resource for special education. The funds saved from the closure of Campbell Park were transferred directly to the schools to which the students returned in the form of "support teams" and individual funding.

\section{Establishment of Support Teams}

A joint project team was established with personnel from the Department of Education Special Education Division and staff of Auckland and Otago Universities. Seventeen school-based support teams were established with researched models in Auckland, Tauranga and Dunedin (Moore, Glynn \& Gold, 1993). Teachers selected for their existing skills and knowledge of special needs, together with effective interpersonal skills, were trained to "maintain students in the mainstream by supporting classroom teachers in the development of their resources and programmes for students" (Moore \& Sheldon, 1989, p. 5). Support teachers were advised and supported by psychologists from the psychological service. By 1990, 69 schools had support teams.

The implementation of support teams enabled the return to their local community school of students who had been segregated, and provided support to enable the teachers and schools to create classrooms that met these students' educational needs. In a review of the support teams, Moore, Glynn and Gold (1993) noted a number of concerns:

- The majority of principals selected staff without consultation with special educators and failed to provide training for fully one third of appointees.

- Many principals failed to ensure the establishment of a management team to support the specialist teacher.

- Secondary schools were less likely to make provision for training and more likely to use withdrawal rather than the intended teacher support model. They were also less likely to have a management committee to support the teacher.

- Where support teachers were trained and supported by an active management committee, they were more likely to engage in the intended in-class support and less likely to have their role "eroded into pupil withdrawal and one-to-one remedial tutoring" (p. 201).

- Parental involvement was minimal.
Despite the carefulimplementation, central administrative support and funding, there was a drift back to the functional limitation paradigm and segregation, wherever teacher selection and training, and management committee support were inadequate. This was particularly evident in secondary schools. The drift away from the model was also a result of the centripetal/centrifugal tension. With the move away from central to local operational control, principals were free to avoid the policy requirements and many did, a phenomenon discussed later in this paper.

The universities team (Moore \& Sheldon, 1989) noted the influence of the Curriculum Review (1987) and the Draft Review of Special Education (Department of Education, 1987) in the development of the support team model. The Draft Review of Special Education had suggested a significant change, proposing the following fundamental principles for special education. It should be:

- universal,

- integral with other education programmes,

- lifelong,

- unified across sectors, home and school,

- needs based,

- effective and accountable.

The Draft Review went on to note that, "To achieve the ultimate aim of normalization through mainstreaming it will be necessary to move to a single stream of education with special education acting as a support service" (p. 93). Among the proposed sequential steps to achieve this aim, the review suggested, inter alia:

- Decisions on educational planning including resource allocations to be developed as far as possible for local action within national guidelines.

- Introduction of procedures whereby parents and the community can become more involved in planning and participation in special education. It will be necessary to ensure that cultural and ethnic differences are catered for.

- A comprehensive review of pre-service, specialist and in-service training for all involved in special education, including non-teaching staff.

- The recognition of educational practice based on individually assessed needs and teaching programmes provided in a form that permits accountability. 
- The establishment of a significant number of special education support units based upon the guidance unit model and aimed at the generic support for students with special teaching needs already in regular educational facilities.

The Draft Review of Special Education had set the scene for fundamental changes in special education. Jack Bardon, one of the most influential special educators in the United States at the time and a writer on international developments in special education, commented that "The proposal capitalises on at least two decades of socio-political ferment related to the needs and rights of children and recognises and proposed approaches based on current expert opinion and the body of research." (Personal communication, June 29, 1987). It had led to alterations of the Education Amendment Act 1989, which ensured all children in New Zealand would receive education as of right.

However the Draft Review was put on hold with the arrival of Tomorrow's Schools. Butterworth and Butterworth (1998), in reviewing progress in special education since the Draft Review, noted that three of the recommendations survived the reform process of 1988-89. They were:

- to ensure that educational provisions for students with special need were as normal as possible;

- to establish a process involving parents, the community, the students, and educators to decide the best way to assist any student;

- to emphasise individual assessment and programme development. (p. 189)

The Tomorrow's Schools reforms and the subsequent curriculum reforms did not specifically address special education. They did however have major implications for it, both in the understanding of how successful learning occurs and in the specification of schools' responsibility towards student learning.

\section{National Administrative Reforms}

These reforms, which changed school governance from a centralised to a largely decentralised system, required schools to establish policies and practices to meet the needs of their particular students within nationally determined education guidelines (NEGs). The national guidelines specified national goals, administrative guidelines (NAGs) and a national curriculum framework (NZCF) aiming to provide better learning opportunities for all students and particularly students with special needs (Ministry of Education, 1997a). Hence an official position was established in mainstream education of equitable rights for learning for all students and recognition of the impact of the quality of teaching on student learning.

When the revised NAG 1 (Ministry of Education, 1993a) made it mandatory for schools to identify barriers to learning and implement strategies to overcome these barriers, a distinctly different perspective was placed on learning difficulty from that implicit in the functional limitation model. Elaboration of possible barriers was provided in the Ministerial kit Governing and Managing New Zealand Schools: A Guide for BOT (Ministry of Education, 1997a). In this document, attention was drawn to the environmental influences which impact on students' learning, including "administration structures and teacher behaviours" (p. 17), advocating that these factors should be considered in the identification process before determining changes to meet students' needs more effectively. Furthermore, the suggested identification process involved collecting and analysing data on present needs and achievements for individual students and groups of students, in collaboration with diagnostic and support services. Again the attention is on the impact of the educational environment on educational success and the need for teachers to take a central position in monitoring this situation.

The official policy for teaching, learning and assessment in New Zealand schools provides further evidence of an ecological, educational stance towards learning difficulties. The NZCF (Ministry of Education, 1993b) stresses the interrelatedness of knowledge and skills in the learning areas, the ongoing developmental nature of learning and the desirability for schools to develop programmes based on the interests and needs of their particular students, reflecting a constructivist perspective tolearning. Consistent with constructivist theory, the NZCF emphasises an integrated teaching and learning cycle. Teaching is viewed as being responsive to individual learning need and consequently requires diagnostic assessment procedures and adaptive teaching strategies. The NZCF envisages teachers planning lessons based on related objectives but at different levels, providing a range of concurrent activities and developing different criteria for success for different students (Ministry of Education, 1997b). According to the NZCF these are the skills required by all teachers to teach all students. 
Furthermore, as Thomson (1998) observes, the NZCF specifies very clearly that "all" students does in fact mean all students when it states that:

The school curriculum will recognise, respect, and respond to the educational needs, experiences, interests, and values of all students; both female and male students; students of all ethnic groups; students with different abilities and disabilities; and students of different social and religious backgrounds. Inequalities will be recognised and addressed. (p. 7)

Recent revision of NAG 1 and 4 in November, 1999 (Ministry of Education, 1999b) places renewed emphasis on the central purpose of schools being for all students to learn successfully. The revised NAG 1 requires schools to identify students and groups of students "who are not achieving, who are at risk of not achieving, who have special needs and aspects of the curriculum which require special attention"; and to "develop and implement teaching and learning strategies to address the needs of students" (p. 5). This reflects a growing expectation that all students can successfully learn in the regular classroom given appropriate opportunities, and places the NAGs soundly within the inclusion paradigm.

Special attention for improving Maori achievement in consultation with the Maori community is also targeted. This reflects the ministerial Maori Education Strategy with its first goal "to make mainstream schools more accountable and responsive to the needs of Maori students and parents" (Velde, 1999, p. 1). Again the focus is on schools being accountable for providing a suitable learning environment.

The revised NAG 2 places the process for accountability (through school review) alongside NAG 1. For the first time teacher professional development is identified as the means of meeting students' learning needs. The implication is that teachers can and must provide a successful learning environment for all their students.

\section{Special Education 2000}

In 1996 the government announced a new special education policy, Special Education 2000 (SE2000). This policy can be seen to encompass the recommendations of the Draft Review of Special Education of 1987, the removal of administrative categories of disability, national guidelines for schools to set priorities for the allocation of resources for special needs, a new emphasis upon teacher training to meet special needs in regular schools and classes, support systems for mainstream settings, inservice training for regular class teachers, specialist training for resource personnel including an urgent need "in establishing support for students and teachers" (p. 91)

The developments in curriculum and administration in the intervening years had provided a more facilitative climate for such a policy, although its implementation has not been without challenges.

In 1998, 500 special education teachers in New Zealand schools (special, experience and assessment class teachers and teachers providing itinerant special needs support in learning and behaviour) were translated into Resource Teachers: Learning and Behaviour (RTLB). In addition approximately 225 new positions were created to ensure a teacher: student ratio of 1:750 (Brodie, 1998). This is a provision to support students with mild to moderate need. The policy also provides additional resources and support for students with high to very high need. In establishing these RTLB positions the government acknowledged the importance of specific training. This had been stressed earlier in the Draft Review and in the report on support teams by Moore et al. (1993).

The Ministry of Education and Specialist Education Service (SES), which were given the responsibility for providing the training to ensure these teachers were able to carry out this new role, decided that this needed to be at a graduate/post graduate level, providing the teachers with a meaningful addition to their existing qualifications (Brodie, 1998). The SES contracted a consortium of three universities, Auckland, Waikato and Victoria University of Wellington, to develop a professional development programme for the RTLB that would consist of four papers at a graduate or post graduate level (depending on the prior qualifications of the RTLB).

The programme is designed so that on completion the RTLB will have achieved the following graduate profile:

1. Work to a high professional and ethical standard;

2. Recognise and promote the bicultural nature of the New Zealand education system;

3. Work to ensure equitable educational opportunity for all learners;

4. Follow an educational model;

5. Work to a collaborative consultation model;

6. Be skilled practitioners and promoters of effective teaching skills;

7. Be reflective practitioners. 
The developers of the programme proposed a theory of effective RTLB practice (see Fig 1).

\section{Figure 1}

\section{A THEORY OF EFFECTIVE RTLB PRACTICE}

KNOWLEDGE \& UNDERSTANDING

ATTITUDES \& PRACTICE

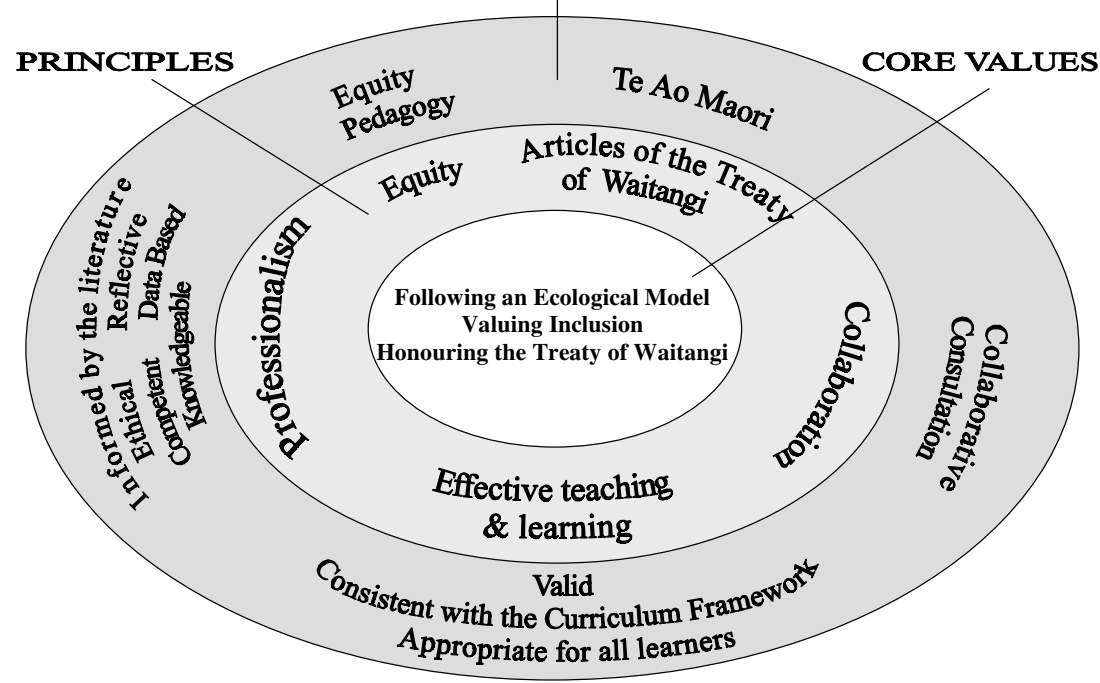

This is consistent with the requirements of the SE2000 policy that the RTLB take a pivotal role in the establishment of inclusive education in New Zealand. The professional development programme designed to ensure the RTLB are equipped for this role identifies five distinct themes.

\section{A collaborative consultative model of problem solving in service} delivery

For many of the teachers undertaking the role of the RTLB there will be a major change in the way they work. As Glynn (1998) succinctly puts it, "The RTLB has the challenging task of supporting all those 'other' teachers to take up their individual and collective responsibility for the learning and behaviour of all the students in their classes and school" (p. 5). This approach of working with others as agents of change is consistent with the ecological paradigm that recognises that the learning and behaviour of students is a result of the interaction between the student and the learning context. If a change is to occur it will be as a result of changes in this interrelationship and the class teacher is crucial to this process. An important aspect of this theme of the programme derives from a constructivist view of learning, stressing that if effective and lasting change is to take place, it will do so when the class teacher has played a major role in defining the problem and developing the solutions.

\section{A focus upon an inclusive teaching philosophy which recognises} and values diverse strengths irrespective of age, gender, ethnicity, ability/ disability

The fundamental notion of inclusive education is that it is the task of the school and community to create environments that meet the needs of all learners. (Stainback \& Stainback, 1990). This requires classroom teachers to cater for the diverse range of students in their classrooms and for RTLB to support them in developing and maintaining teaching practices that create inclusive classrooms.

The RTLB programme includes a range of inclusive teaching strategies including cooperative learning (Johnson \& Johnson, 1989), strategic teaching (Brown, 1992), reciprocal teaching (Westera \& Moore, 1995), Hikairo Rationale (Macfarlane, 1997) and peer tutoring (Medcalf, 1995). Not only are the RTLB required to implement effective programmes using these methodologies as part of their course work, but faculty teaching in the programme model strategies, especially cooperative learning, in block sessions.

3. An educational / ecological approach to assessment and intervention, utilising applied behaviour analysis and data-based decision making strategies

As this approach places emphasis on the learner in interaction with the learning environment, the RTLB must now be able to analyse the crucial features of this environment in addition to the characteristics of the learner (such as academic performance) with which most RTLB are more familiar. TIES II, the Instructional Environment System(Ysseldyke \& Christensen, 1993) has been adopted as a fundamental assessment instrument that enables the RTLB to identify a student's instructional needs within the learning environment. 
The applied behaviour analysis perspective is also adopted in the programme. There is an emphasis on changing behaviour by analysis and intervention in the context in which the behaviour is occurring. An understanding of how behaviour is shaped by both antecedent and consequent events is therefore required. A commitment to data-based decision making and evaluation is fundamental to such an approach.

\section{Acknowledgment of cultural values and preferred practices from} within a Maori world view

The need for RTLB to be effective in supporting teachers of Maori students is clearly evidenced by the high representation of Maori among students experiencing learning and behaviour difficulties (Macfarlane, 1998). There has been a commitment in the development and delivery of the programme that RTLB have an understanding of Maori perspectives on human development, learning and teaching and the implications of honouring the Treaty of Waitangi, especially Article Two (a).

\section{Reflecting on and evaluating professional practice}

The programme encourages RTLB to reflect on their professional practice in a number of ways. They are encouraged to consider their practice in terms of its effectiveness, its consistency with their own assumptions and beliefs, its consistency with best practice and with the role of the RTLB as defined in SE2000.

Each of the four papers addresses these perspectives with 25 percent of the content and assessment tasks of each paper devoted specifically to cultural values and preferred practices within a Maori world view.

There is now a nationally recognised resource teacher position with specifically designed professional training. This position exists within a policy framework of both special and regular education that supports the inclusion paradigm. It has taken 25 years to reach this point. However given the multiparadigmatic nature of our society, progress in achieving a national RTLB service may still be slow.

As the professional development programme began, Brown (1998) identified a number of potential tensions for the RTLB as they made the transition to their new role. He noted that, "Not only must they assimilate a new model in conceptual terms, but they must also have the will to apply it" (p. 12). The group of teachers taking up these new positions can be seen to represent the whole paradigmatic spectrum, from a significant number who have worked and currently undertake their RTLB position in separate special classes, to those who have worked for some time as itinerant teachers in a role very similar to this new one. Prior to taking up the RTLB position, approximately two thirds of the group had worked in special education, largely within the functional limitations paradigm (Brown et al., 1999). Consequently there is a great variation in both the conceptual understanding of the role and the willingness to engage in it.

RTLB are required by the definition of their role to work with others as agents of change for the students they support. These agents are primarily class teachers. Many of these teachers have been accustomed to itinerant teachers removing students for individualised instruction, and may struggle with the expectation that they now accept the primary responsibility for the student's programme. RTLB report responses ranging from hostility through bewilderment to ready acceptance when they attempt to develop a collaborative plan for a class-based programme.

A further tension arises from strain between central control and decentralisation (Mitchell, 1999). The RTLB positions were established by a national policy. The organisational structure for these positions, based on clusters, is formalised in a memorandum of agreement signed by boards of trustees of cluster schools with the Ministry of Education. This memorandum sets out the description and purpose of the position, the training requirements and the management structure. However, in the present climate of school self management, management committees have been able to deploy the RTLB in ways other than those outlined in the job description. Consequently there are a number of RTLB who currently teach full time in separate special classes for which an alternative staffing component is provided. Those in itinerant roles have management committees, some of which may have little or no understanding of, or commitment to, the inclusive/ ecological paradigm (Walker et al., 1999). Management committees act as "street level bureaucrats" (Weatherley \& Lipsky, 1977) who work within the constraints of the resource provision to ensure the delivery of the policy as they define it, not always consistent with the intention of SE2000. This seems to be an example of what Rae (1998) describes as "an ongoing tension between equity as a goal and choice as a means of responsiveness and effectiveness" (p. 492).

For a paradigm to take hold, it is necessary for it to gather to itself a critical mass of support. Brown and Thomson (1990) tell the story of the "hundredth monkey" - an analogous tale of winning support for a 
new behaviour. In a tribe of monkeys one discovers how to wash their food before eating it. The behaviour is slowly picked up the other monkeys but does not become tribal practice until the hundredth monkey is won over. This story was told in relation to mainstreaming and inclusion. The point was made that we had not yet reached the hundred th monkey. It appears ten years later that while we now have a policy which validates the behaviour, we still have some way to go before we see complete acceptance of the paradigm.

Despite the difficulties, there are many situations throughout the country where the implementation of this new role has been sound and robust. This is occurring where RTLB who have enthusiastically embraced the inclusive paradigm have worked with high levels of skill alongside receptive class teachers who also are committed to inclusive education. These RTLB have been facilitated by supportive management committees and principals who work energetically and innovatively with them "to find the best possible learning environment and learning strategies for each student" (Fancy, 1998, p. 3). Such situations are clear evidence of the words of Michael Fullan, a leading authority in educational change.

Reform in special education represents just about all the issues involved in bringing about educational reform. The solutions to inclusion are not easily achieved. It is complex both in the nature and degree of change required to identify and implement solutions that work. Given what change requires - persistence, co-ordination, follow-up, conflict resolution and the like - leadership at all levels is required. (UNESCO, 1994, p. 39 )

\section{References}

Ballard, K., \& McDonald, T. (1998). New Zealand: Inclusive school, inclusive philosophy? In T. Booth \& M. Ainscow (Eds.), From them to us: An international study of inclusion in education. (pp. 69-94). London: Routledge.

Brodie, J. (1998, July). Background and development of Special Education 2000: New initiatives in special education. Paper presented at the 28th Annual Conference, Australian Teacher Education Conference, Melbourne.

Brown, D. (1992). The development of strategic classrooms in two secondary schools. Waikanae: Wordsmiths.

Brown, D. (1998, July). An educational model and professional development for resource teachers. Paper presented at the 28th Annual Conference, Australian Teacher Education Conference, Melbourne.

Brown, D., Moore, D., Thomson, C., Anderson, A., Walker, J., Glynn, T., Macfarlane, A., \& Ysseldyke, J. (1999, September). Resource teachers learning and behaviour: An ecological approach to special education. Paper presented to the Annual Conference of the Australian Association of Special Education, Sydney, Australia.

Brown, D. F., \& Thomson, C. (1988, July). How do we get to there from here? Paper presented to the Conference of the New Zealand Institute of Mental Retardation (Inc). Community integration for people with intellectual handicaps "Good News" conference, Dunedin.

Brown, D. F., \& Thomson, C. (1990). The hundredth monkey: Thoughts on change and parent advocacy. I H Review, 28(4), 9-13.

Butterworth, G., \& Butterworth, S. (1998). Reforming education: The New Zealand experience, 1984-1996. Palmerston North: Dunmore Press.

Davies, T., \& Prangnell, A. (1999, February). Special Education 2000 - A national framework. Address given at Special Education 2000 Research Conference, Auckland, New Zealand.

Department of Education. (1967). The draft review of education. Wellington: Department of Education.

Fancy, H. (1999, February). Opening address given at Special Education 2000 Research Conference, Auckland, New Zealand.

Gerritsen, J. (1999). Guideline changes welcome. The Education Gazette 78(22), $1-5$.

Glynn, T. (1998, July). A collaborative approach to teacher development: New initiatives in special education. Paper presented at the 28th Annual Conference, Australian Teacher Education Conference, Melbourne.

Johnson, D., \& Johnson, R. (1989). Cooperation and competition: Theory and research. Edina, $\mathrm{MN}$ : Interaction Book $\mathrm{Co}$

Kuhn, T. S. (1962). The structure of scientific revolutions. Chicago: University of Chicago Press.

Lincoln, Y. S. (Ed.). (1985). Organisational theory and inquiry: The paradigm revolution. Beverly Hills, CA: Sage Publications.

Macfarlane, A. (1997). Teaching students with emotional and behavioural difficulties: A bicultural approach. Waikato Journal of Education, 3, 153-168.

Macfarlane, A. (1998, July). Piki Ake te Tikanga: Culture counts in special education. Paper presented at the 28th Annual Conference, Australian Teacher Education Conference, Melbourne.

Medcalf, J. (1995). Cooperative learning and peer tutoring: Strategies for inclusive education. Reading Forum NZ, 2, 11-19.

Mitchell, D. (1999). Special education in New Zealand: A decade of change. New Zealand Journal of Educational Studies, 34(1), 199-210.

Ministry of Education. (1993a). Official Notice. The Education Gazette 72(7), 3. Ministry of Education. (1993b). The New Zealand Curriculum Framework. Wellington: Learning Media.

Ministry of Education. (1994). English in the New Zealand curriculum. Wellington: Learning Media. 
Ministry of Education. (1996). Special Education 2000. Wellington: Ministry of Education.

Ministry of Education. (1997a). Governing and managing New Zealand schools: A guide for board of trustees. Part One: The National Education Guidelines. Wellington: Learning Media.

Ministry of Education. (1997b). Planning and assessment in English. Wellington: Learning Media.

Ministry of Education. (1999a). Resource teachers: Learning and behaviour Information for RTLBs and clusters. Wellington: Ministry of Education.

Ministry of Education (1999b). The Education Gazette, 78(15), 25.

Moore, D., Anderson, A., Timperley, H., Glynn, T., Macfarlane, A., Brown, D., \& Thomson, C. (1999). Caught between stories: Special education in New Zealand. Wellington: NZCER.

Moore, D., Glynn, T., Gold, M. (1993). Enhancing teachers' skills in special education: Support teams in New Zealand schools - Establishment and practice. Report to the Ministry of Education.

Moore, D., \& Sheldon, L. (1989, March). Support teams, special education and the classroom teacher. Working Paper 1. Paper presented to the National Support Teams Conference, Wellington, New Zealand.

Rae, K. (1998, January). Whakaritorito te tupu o te harakeke - growing the flax shoots: Dilemmas of devolution in New Zealand schools. Paper presented to the biennial conference of NZEAS, Wellington, New Zealand.

Ritzer, G. (1980). Sociology: A multiple paradigm science. (Rev.ed.). Boston: Allyn and Bacon. Ritzer, G. (1983). Sociological Theory. (2nd ed.) . New York: Alfred A. Knopf.

Skrtic, T. M. (1986). The crisis in special education knowledge: A perspective on perspectives. Focus on Exceptional Children, 18(7), 1-16.

Skrtic, T. M. (1991). The special education paradox: Equity as a way to excellence. Harvard Educational Review, 61(2), 148-206.

Skrtic, T. M. (1995). The special education knowledge tradition: Crisis and opportunity. In F. L. Meyen \& T. M. Skrtic (Eds.), Special education and student disability: An introduction (4th ed., pp. 569-607). Denver, CO: Love Publishing Company.

Sleeter, C. (1995). An analysis of the critiques of multi-cultural education. In J. Banks \& C. Banks (Eds.), Handbook of research on multi-cultural education. New York: McMillan Publishing.

Stainback, S., \& Stainback, W. (1990). Inclusive schooling. In W. Stainback \& S. Stainback (Eds.), Support networks for inclusive schooling (pp. 3-23). Baltimore: Paul Brookes.

Thomas, J. D., \& Glynn, E. (1976). Mangere guidance unit: Evaluation of behavioural programmes. Final report to the Director General of Education. Auckland: Auckland University.
Thomson, C. (1998, July). Inclusion and professional development for resource teachers. Paper presented at the 28th Annual Conference, Australian Teacher Education Conference, Melbourne.

UNESCO. (1994). Final report. World conference on special needs education: Access and quality. Salamanca, Spain: UNESCO.

Velde, M. (1999). Strategy against disparity. The Education Gazette 78(15), 1-5.

Walker, J., Moore, D., Anderson, A., Brown, D., Thomson, C., Glynn, T., Macfarlane, A., \& Medcalf, J. (1999). Innovative inclusion initiative: The resource teachers in learning and behaviour programme. Paper presented at the AARE-NZARE Conference, Melbourne, Australia.

Weatherley, R., \& Lipsky, M. (1977). Street-level bureaucrats and institutional innovation: Implementing special-education reform. Harvard Educational Review, 47(2), 171-197.

Westera, J., \& Moore, D. (1995). Reciprocal teaching of reading comprehension in a New Zealand high school. Psychology in Schools, 81, 283-293.

Ysseldyke, J., \& Christenson, S. (1993). TIES II: The instructional environment system II. Longmont, CO: Sopris West.

\section{The authors}

Charlotte Thomson, previously a teacher, psychologist and Director of School of Special Education at Wellington College of Education, is at present a senior lecturer on the RTLB professional development programme at Victoria University of Wellington. Since 1990 she has worked principally as a teacher educator and consultant to schools.

Don Brown presently directs the RTLB professional development programme at Victoria University of Wellington. He has worked as a teacher and psychologist in New Zealand and the United Kingdom. For some years he was Chief Psychologist and then Director, Special Education in the New Zealand Department of Education. Since 1990 he has worked actively as a consultant and teacher educator in primary and secondary schools, colleges of education and at Victoria University of Wellington. He was awarded the New Zealand 1990 Commemoration Medal for services to education. He is a fellow of the New Zealand Psychological Society.

Elizabeth Jones is a lecturer in the RTLB professional development programme at Victoria University of Wellington. She has worked for the last six years in teacher education. She has worked in New Zealand education since 1976 and has been a teacher, primary school principal and psychologist.

Elizabeth Manins is currently a lecturer in Special Education at Wellington College of Education. She has been involved in teaching at early childhood, primary and tertiary level in both special and general education since the 1970s. 